\title{
Blood lactate thresholds and walking/running economy are determinants of backpack-running performance in trained soldiers
}

\author{
Richard J. Simpson, ${ }^{\mathrm{a}, \mathrm{b}, ~ *}$ Scott M. Graham, ${ }^{\mathrm{b}}$ Christopher Connaboy, ${ }^{\mathrm{c}}$ Richard Clement, ${ }^{\mathrm{b}}$ Luca Pollonini, ${ }^{\mathrm{d}}$ \\ Geraint D. Florida-James ${ }^{b}$ \\ ${ }^{a}$ Laboratory of Integrated Physiology, Department of Health and Human Performance, University of Houston, 3855 Holman Street, Houston, TX 77204, USA \\ ${ }^{\mathrm{b}}$ Biomedicine and Sports Science Research Group, School of Life, Sport and Social Sciences, Edinburgh Napier University, Edinburgh EH11 4BN, Scotland, UK \\ ${ }^{c}$ Neuromuscular Research Laboratory, Warrior Human Performance Center, University of Pittsburgh, Pittsburgh, PA 15213, USA \\ ${ }^{\mathrm{d}}$ Abramson Center for the Future of Health, Department of Engineering Technology, University of Houston, 4300 Calhoun Road, Houston, TX 77004, USA
}

\section{A R T I C L E I N F O}

Article history:

Received 6 August 2015

Received in revised form 18 April 2016

Accepted 19 April 2016

Available online $\mathrm{xxx}$

Keywords:

Load-carriage

Ventilatory threshold

Special forces

\section{A B S T R A C T}

We developed a standardized laboratory treadmill protocol for assessing physiological responses to a simulated backpack load-carriage task in trained soldiers, and assessed the efficacy of blood lactate thresholds (LTs) and economy in predicting future backpack running success over an 8-mile course in field conditions. LTs and corresponding physiological responses were determined in 17 elite British soldiers who completed an incremental treadmill walk/run protocol to exhaustion carrying $20 \mathrm{~kg}$ backpack load. Treadmill velocity at the breakpoint $(\mathrm{r}=-0.85)$ and $\Delta 1 \mathrm{mmol} \mathrm{l}^{-1}(\mathrm{r}=-0.80)$ LTs, and relative VO2 at $4 \mathrm{mmol}^{-1}(\mathrm{r}=0.76)$ and treadmill walk/run velocities of $6.4(\mathrm{r}=0.76), 7.4(\mathrm{r}=0.80), 11.4$ $(\mathrm{r}=0.66)$ and $12.4(\mathrm{r}=0.65) \mathrm{km} \mathrm{h}^{-1}$ were significantly associated with field test completion time. We report for the first time that LTs and backpack walk/run economy are major determinants of backpack load-carriage performance in trained soldiers.

(C) 2016 Published by Elsevier Ltd

\section{Introduction}

Soldiers who aspire to serve in the elite units undergo rigorous selection procedures, with the ability to carry backpacks at speed over undulating and/or arduous terrain being key to their success (Allsopp and Shariff, 2004; Wilkinson et al., 2008). As attrition rates are typically high, identifying the physiological underpinnings of successful backpack load-carriage performance is important to generate valid discriminative entry-level physical assessments and to develop adequate training regimens for aspiring recruits (Rayson et al., 2000). The physiological determinants of backpack load-carriage performance are likely to include measures of strength, body composition and endurance (Haisman, 1988; Rayson et al., 2000). The maximal oxygen uptake (VO2max), regarded as the 'gold standard' measure of maximal aerobic capacity, is positively associated with non-load-carrying endurance performance (i.e. running), and has been correlated with successful load-carriage performance also (Rayson et al., 2000). Conversely, many studies have found $\mathrm{VO} 2 \mathrm{max}$ to be a weak determinant of successful load-carriage (Bilzon et al., 2001), even when peak oxygen uptake is measured during a prior load-carriage task (Simpson et al., 2006). The ambiguity surrounding VO2max could be due to inconsistencies in experimental design, including backpack weight, the performance outcome measure (i.e. maximum weight carried or time taken to carry a fixed weight over a set distance), and

\footnotetext{
* Corresponding author. Laboratory of Integrated Physiology, Department of Health and Human Performance, University of Houston, 3855 Holman Street, Houston, TX 77204, USA.

Email address: rjsimpson@uh.edu (R.J. Simpson)
}

whether VO2max was measured during a load or non-load carrying task, and the training status of the participants (i.e. civilians, conventional soldiers, or elite soldiers).

For tasks that do not involve load-carriage, submaximal physiological parameters are often preferred over VO2max to predict endurance performance. The blood lactate threshold (LT), although widely varied in concept and interpretation, is generally defined as the absolute workload above which blood lactate levels rise exponentially during incremental exercise (Faude et al., 2009; Weltman, 1995). This rise usually occurs concomitantly with a disproportionate increase in minute ventilation relative to oxygen uptake, a concept known as the ventilatory threshold $\left(\right.$ Vent $^{\mathrm{T}}$ ) (Gaskill et al., 2001). The LT is believed to represent an increased involvement of the anaerobic energy pathways to provide ATP and has been shown to be superior to VO2max when predicting endurance performance in homogenous groups of athletes (Faude et al., 2009). Moreover, the oxygen cost of running at a given submaximal speed (referred to as economy) and the ability to maintain high percentages of the $\mathrm{VO} 2 \mathrm{max}$ without substantial increases in blood lactate concentration, are also useful indicators of performance in endurance athletes (Saunders et al., 2004).

Despite the success and ubiquitous use of LTs, Vent ${ }^{\mathrm{T}}$ and running economy as predictors of endurance performance in athletes (Faude et al., 2009; Saunders et al., 2004), no previous studies have attempted to identify the efficacy of these variables as determinants of backpack load-carriage performance, or their effectiveness for predicting future success in field based load-carriage tasks. Moreover, while there is a large body of normative data available on the physiological responses to simulated backpack load-carriage tasks in conventional military troops (Beekley et al., 2007; Christie and Scott, 
2005; Rayson et al., 2000) and recreationally active males (Faghy and Brown, 2014), comprehensive physiological data on elite soldiers are lacking (Simpson et al., 2006, 2010; Wilkinson et al., 2008).

Our aim in this study was to determine the physiological values associated with a simulated backpack load carriage task in a controlled laboratory setting, using an incremental treadmill protocol for a homogenous group of elite soldiers, and to establish the efficacy of the measured physiological variables for predicting future performance of a backpack load carriage task conducted in a field setting. We hypothesised that LTs and backpack walking/running economy would be associated with the time taken to complete an 8-mile backpack running test in this group of trained soldiers.

\section{Methods}

\subsection{Participants}

Seventeen male soldiers of the British Army volunteered to participate in this study. All participants were serving with the Parachute Regiment or the Special Air Service (SAS) Regiment and had previously passed pre-parachute selection (P-Company) and/or United

Table 1

Physical and performance characteristics of the participants $(n=17)$.

\begin{tabular}{|c|c|c|}
\hline & Mean $\pm \mathrm{SD}$ & Range \\
\hline Age (yrs) & $25.9 \pm 4.3$ & $21-35$ \\
\hline Height (cm) & $180.1 \pm 6.3$ & $168.5-189.5$ \\
\hline Mass (kg) & $79.3 \pm 6.5$ & $67-87.4$ \\
\hline $\begin{array}{l}\text { Backpack load (\% body } \\
\text { mass) }\end{array}$ & $25.9 \pm 4.3$ & $22.9-29.9$ \\
\hline $\operatorname{VO}_{2 \text { peak }}\left(1 \mathrm{~min}^{-1}\right)$ & $4.34 \pm 0.38$ & $3.60-4.87$ \\
\hline $\mathrm{VO}_{2 \text { peak }}\left(\mathrm{ml} \mathrm{kg}^{-1} \mathrm{~min}^{-1}\right)$ & $55.0 \pm 5.2$ & $46.0-62.3$ \\
\hline HRmax (beats $\min ^{-1}$ ) & $196 \pm 10$ & 174-207 \\
\hline $\begin{array}{l}\text { Maximal blood lactate } \\
\left(\mathrm{mmol} \mathrm{l}^{-1}\right)\end{array}$ & $9.8 \pm 1.7$ & $6.4-12.9$ \\
\hline $\begin{array}{l}\text { Maximal treadmill time } \\
(\min : \mathrm{sec})^{\mathrm{a}}\end{array}$ & $23: 30 \pm 0: 52$ & $21: 00-24: 24$ \\
\hline $\begin{array}{l}\text { 8-mile backpack run time } \\
(\mathrm{h}: \min : \mathrm{sec})^{\mathrm{b}}\end{array}$ & $1: 28: 38 \pm 0: 04: 27$ & $1: 21: 50-1: 34: 25$ \\
\hline
\end{tabular}

a Does not include the 60-s intervals after each incremental stage of the protocol.

b Data obtained from ten participants only.
Kingdom Special Forces (UKSF) selection prior to their participation in this study. We previously compared selected physiological variables and performance markers between soldiers of these two regiments and found no discernable differences (Simpson et al., 2006). All participants completed and passed their unit specific annual physical fitness tests within the preceding 12-months of the study and refrained from strenuous physical activity for $48 \mathrm{~h}$ before participating in the exercise trials. All participants provided written informed consent and institutional ethical approval was granted. The physical characteristics of the participants are presented in Table 1.

\subsection{Pre-exercise measures}

On arrival to the laboratory, height and body mass (nude) of each participant was recorded. Participants wore standard issue combat trousers, military style boots (according to individual preference) and a T-shirt, were fitted with a heart rate monitor (S610, Polar Electro, Kempele, Finland), and asked to rest on a plinth in the supine position for $10 \mathrm{~min}$. After the rest period, ratings of perceived exertion (RPE), using the Borg 6-20 scale (Borg, 1998), and heart rate were recorded, and a capillary blood sample was collected from the earlobe to determine blood lactate concentration [assayed in duplicate using an automated analyser (P-GL5, Analox Instruments, London, UK)]. Each participant was then fitted with a face-mask, which was connected to the online gas analysis apparatus (CPX Medgraphics, Oldham, UK), and asked to rest in a seated position for $5 \mathrm{~min}$. During this period, mean minute ventilation (VE), oxygen uptake (VO2), expired carbon dioxide (VCO2), the respiratory exchange ratio (RER) and the ventilatory equivalent of oxygen (VE/VO2) and carbon dioxide (VE/VCO2) were recorded.

\subsection{Backpack treadmill-running protocol}

The Backpack-Treadmill Running Protocol is depicted in Fig. 1. After obtaining the resting measures, each participant put on a standard British Army Bergan (backpack), which weighed $20 \mathrm{~kg}$ and was previously packed prior to testing and checked for individual comfort. A discontinuous backpack running protocol was then completed on a motorised treadmill (Woodway Ergo ELG 55, Weil am Rhein, Germany). The protocol began with the subject walking on a $+1 \%$ in-

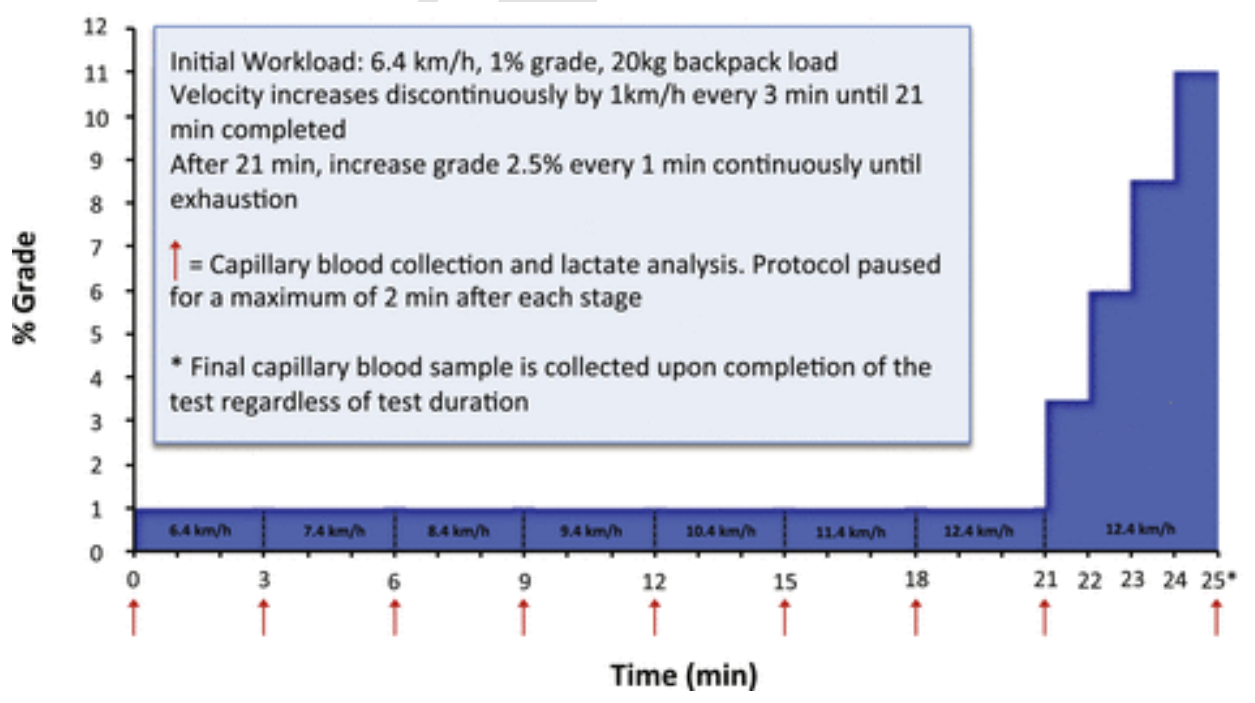

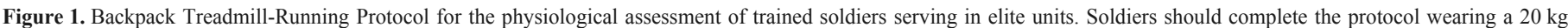
backpack load and combat boots. 
cline at a velocity of $6.4 \mathrm{~km} \mathrm{~h}^{-1}$. The treadmill was set at a $1 \%$ gradient to best mimic outdoor running conditions (Jones and Doust, 1996). The velocity of the treadmill was increased by $1.0 \mathrm{~km} \mathrm{~h}^{-1}$ every $3 \mathrm{~min}$ until a maximal running velocity of $12.4 \mathrm{~km} \mathrm{~h}^{-1}$ was attained. After each 3 min stage of exercise, the participant straddled the treadmill for a 1 min period to allow a capillary blood sample to be taken for subsequent blood lactate analysis and provided their RPE score. After obtaining RPE and the capillary blood sample following the period of maximal running velocity $\left(12.4 \mathrm{~km} \mathrm{~h}^{-1}\right)$, the participants stepped back on the treadmill with the velocity maintained at $12.4 \mathrm{~km} \mathrm{~h}^{-1}$ and the inclination set at $+3.5 \%$ and ran continuously, with the inclination of the treadmill increasing by $2.5 \%$ after every subsequent minute until volitional exhaustion. All participants were encouraged to progress as far into the protocol as possible until volitional exhaustion. A final capillary blood sample was taken immediately at the end of the test to determine maximal blood lactate concentration. The RPE was also recorded immediately at the end of the test. Heart rate was recorded continuously during the exercise protocol and averaged over $5 \mathrm{sec}$ intervals. Similarly, breath-by-breath analysis was used to collect respiratory data (VO2, VE, VE/VO2, VE/VCO2), which was also averaged over $5 \mathrm{sec}$ intervals. To reduce the influence of a respiratory lag phase at the beginning of each incremental stage of the discontinuous protocol, only the heart rate and respiratory data obtained during the final 2-min of each stage of the protocol was processed for analysis.

\subsection{Identification of blood lactate and ventilatory thresholds}

Five blood lactate thresholds (LTs) were determined from the backpack treadmill running protocol using the methods described by Weltman (Weltman, 1995). These included: (i) the lactate breakpoint, defined as the highest running velocity attained before an exponential rise in blood lactate concentration; (ii) $\Delta 1 \mathrm{mmol}^{-1}$, defined as the running velocity associated with a blood lactate concentration that is $1 \mathrm{mmol}^{-1}$ greater than the resting lactate concentration; (iii) $2.5 \mathrm{mmol} \mathrm{l}^{-1}$ threshold, defined as the running velocity associated with a blood lactate concentration of $2.5 \mathrm{mmol} \mathrm{l}^{-1}$; (iv) $3.0 \mathrm{mmol} \mathrm{l}^{-1}$ threshold, defined as the running velocity associated with a blood lactate concentration of $3.0 \mathrm{mmol} \mathrm{l}^{-1}$; and (iv) the onset of blood lactate accumulation (OBLA), defined as the running velocity associated with a blood lactate concentration of $4.0 \mathrm{mmol}^{-1}$. The ventilatory threshold $\left(\right.$ Vent $\left.^{\mathrm{T}}\right)$ was identified visually by two independent reviewers as the running velocity at which the ventilatory equivalent of oxygen (VE/VO2) increased without a concomitant increase in the ventilatory equivalent of $\mathrm{CO} 2$ (VE/VCO2) (Gaskill et al., 2001). All measured blood lactate concentrations were plotted on a scatter graph with lactate concentration on the $\mathrm{y}$-axis and treadmill velocity on the $\mathrm{x}$-axis. A line of best fit was applied and two reviewers independently identified the BLTs, which were determined as a function of treadmill running velocity. Relationships were then established between velocity and heart rate, RPE and VO2 to determine equivalent $\mathrm{HR}, \mathrm{VO} 2$ and RPE values ( $r>0.95$ in all cases) that correspond with the velocity at each BLT and the Vent ${ }^{\mathrm{T}}$.

\subsection{Backpack walking/running economy}

The initial starting velocity of $6.4 \mathrm{~km} \mathrm{~h}^{-1}$ was selected because the standard British Army Combat Fitness Test is to march 8-miles $(12.87 \mathrm{~km})$ in under $2 \mathrm{~h}$ and was deemed to be a comfortable starting velocity for this group of soldiers. The relative oxygen uptake $\left(\mathrm{ml} . \mathrm{kg}^{-1} \mathrm{~min}^{-1}\right)$ at all stages of the protocol was determined as a measure of backpack walking or running economy.

\subsection{8-Mile backpack run test}

Participants completed an 8-mile backpack run test (field test) within 4-weeks of performing the treadmill test. The undulating 8-mile course was located in the Leadhills area of South Lanarkshire (Scotland, UK). Underfoot conditions were mostly tarmac ( $\sim 6$ miles) with $\sim 2$ miles consisting of dirt/gravel vehicle tracks. The field test was performed on a mild, dry spring morning between 09:30 and 11:30 h. Temperature ranged between 8 and $13{ }^{\circ} \mathrm{C}$ and relative humidity between $79 \%$ and $86 \%$. Subjects were asked to carry a $20 \mathrm{~kg}$ backpack and complete the 8-mile route in the fastest time possible. Run time was recorded upon completion of the test.

\subsection{Statistical analysis}

All data are presented as mean \pm SD. IBM $^{\circledR}$ SPSS $^{\circledR}$ Statistics Version 20 was used to analyze the data. Independent variables included the measured physiological responses to the backpack treadmill-running protocol and the physiological responses associated with Vent $^{\mathrm{T}}$ and blood lactate thresholds. The dependent variable was performance (run time) on the field test. Pearson's product - moment correlation coefficient (r) was used to determine the strength of the association between the independent variables and the dependent variable, and the coefficient of determination $\left(\mathrm{R}^{2}\right.$ value) was used to represent the goodness-of-fit. Statistical significance was accepted at $\mathrm{p}<0.05$.

\section{Results}

\subsection{Physiological responses to the backpack treadmill running protocol}

All subjects successfully completed the backpack treadmill-running protocol. Peak values obtained from the treadmill test are shown in Table 1. The physiological values recorded at each stage of the protocol (continuous measurements such as VO2 and HR were averaged over the last 120 -s of each stage) are shown in Table 2.

\subsection{Performance indicators of the 8-mile backpack time trial}

Due to operational deployment commitments limiting participant availability, only ten subjects completed the 8-mile backpack time trial. Mean completion time was $88.6 \pm 4.5 \mathrm{~min}$. All physiological variables presented in Tables 1-3 were correlated with performance (run time) during the 8-mile time-trial (field test) (Table 4). None of the physical and performance characteristic measures shown in Table 1 were significantly associated with performance on the field test $(\mathrm{p}>0.05)$. Relative oxygen uptake $\left(\mathrm{ml} \mathrm{kg}^{-1} \mathrm{~min}^{-1}\right)$ at walking/ running velocities of $6.4,7.4,11.4$ and $12.4 \mathrm{~km} \mathrm{~h}^{-1}$, and the respiratory exchange ratio (RER) at running velocities of 10.4 and $12.4 \mathrm{~km} \mathrm{~h}^{-1}$ (Table 4), were significantly associated with field test performance $(p<0.05)$. No other variables measured at each stage of the treadmill protocol were related to performance in the field test $(\mathrm{p}>0.05)$.

Correlation coefficients showing relationships between field-test performance and the measured LTs and Vent ${ }^{\mathrm{T}}$ are presented in Table 5. Treadmill running velocity, rating of perceived exertion (RPE) and RPE (\% of peak) at both the breakpoint and $\Delta 1 \mathrm{mmol}^{-1}$ LTs were significantly associated with performance on the field test 
Table 2

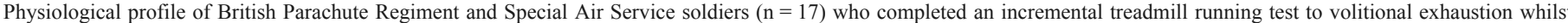

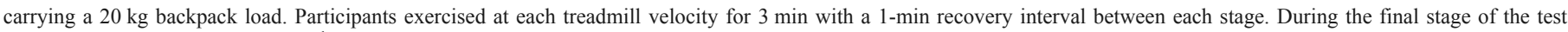

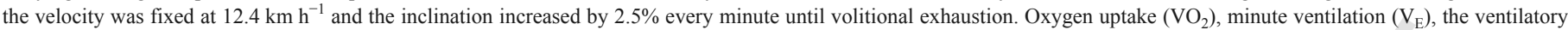

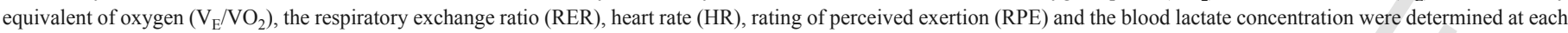
stage of the test. Values are mean \pm SD. Lower and upper limits are shown in parenthesis.

\begin{tabular}{|c|c|c|c|c|c|c|c|c|}
\hline & \multicolumn{7}{|c|}{ Treadmill velocity $\left(\mathrm{km} \mathrm{h}^{-1}\right)$} & \multirow[b]{2}{*}{ Final stage } \\
\hline & 6.4 & 7.4 & 8.4 & 9.4 & 10.4 & 11.4 & 12.4 & \\
\hline $\mathrm{VO}_{2}\left(1 \min ^{-1}\right)$ & $\begin{array}{c}1.84 \pm 0.22 \\
(1.54-2.16)\end{array}$ & $\begin{array}{c}2.41 \pm 0.23 \\
(1.95-2.88)\end{array}$ & $\begin{array}{c}2.95 \pm 0.30 \\
(2.53-3.62)\end{array}$ & $\begin{array}{r}3.04 \pm 0.31 \\
(2.61-3.6)\end{array}$ & $\begin{array}{c}3.25 \pm 0.36 \\
(2.76-3.91)\end{array}$ & $\begin{array}{c}3.47 \pm 0.42 \\
(2.78-4.27)\end{array}$ & $\begin{array}{c}3.71 \pm 0.41 \\
(3.06-4.48)\end{array}$ & $\begin{array}{c}4.0 \pm 0.43^{\mathrm{a}} \\
(3.18-4.77)\end{array}$ \\
\hline $\mathrm{VO}_{2}\left(\mathrm{ml} \mathrm{kg}^{-1} \min ^{-1}\right)$ & $\begin{array}{l}23.6 \pm 2.3 \\
(19.7-27.4)\end{array}$ & $\begin{array}{l}30.5 \pm 2.8 \\
(26.0-35.5)\end{array}$ & $\begin{array}{l}37.3 \pm 3.4 \\
(31.9-42.8)\end{array}$ & $\begin{array}{c}38.4 \pm 3.5 \\
(32.2-44.2)\end{array}$ & $\begin{array}{l}41.0 \pm 3.9 \\
(33.6-46.3)\end{array}$ & $\begin{array}{l}43.9 \pm 4.7 \\
(35.4-51.0)\end{array}$ & $\begin{array}{c}47.0 \pm 4.6 \\
(39.0-55.2)\end{array}$ & $\begin{array}{c}50.8 \pm 5.5^{\mathrm{a}} \\
(40.5-57.4\end{array}$ \\
\hline $\mathrm{VO}_{2}(\%$ of peak $)$ & $\begin{array}{l}43.0 \pm 3.1 \\
(33.2-47.4)\end{array}$ & $\begin{array}{l}55.6 \pm 3.4 \\
(46.9-59.3)\end{array}$ & $\begin{array}{l}67.9 \pm 3.8 \\
(60.9-74.5)\end{array}$ & $\begin{array}{l}70.0 \pm 4.4 \\
(62.0-76.7)\end{array}$ & $\begin{array}{l}74.6 \pm 4.9 \\
(66.9-83.2)\end{array}$ & $\begin{array}{l}79.9 \pm 5.3 \\
(71.4-88.0)\end{array}$ & $\begin{array}{c}85.5 \pm 4.8 \\
(76.2-94.3)\end{array}$ & $\begin{array}{c}92.5 \pm 3.8^{\mathrm{a}} \\
(82.3-97.0)\end{array}$ \\
\hline $\mathrm{V}_{\mathrm{E}}\left(1 \mathrm{~min}^{-1}\right)$ & $\begin{array}{l}38.3 \pm 5.7 \\
(27.4-46.4)\end{array}$ & $\begin{array}{l}53.3 \pm 6.9 \\
(41.0-67.0)\end{array}$ & $\begin{array}{l}68.7 \pm 7.9 \\
(56.1-86.9)\end{array}$ & $\begin{array}{l}71.4 \pm 8.1 \\
(58.1-88.4)\end{array}$ & $\begin{array}{l}78.6 \pm 10.5 \\
(65.2-101.3)\end{array}$ & $\begin{array}{l}90.2 \pm 14.9 \\
(81.3-129.0)\end{array}$ & $\begin{array}{c}103.4 \pm 17.8 \\
(83.2-152.1)\end{array}$ & $\begin{array}{c}126.8 \pm 12.9^{\mathrm{a}} \\
(98.7-144.8)\end{array}$ \\
\hline $\mathrm{V}_{\mathrm{E}} / \mathrm{VO}_{2}$ & $\begin{array}{c}20.5 \pm 2.0 \\
(17.2-22.6)\end{array}$ & $\begin{array}{l}22.1 \pm 2.0 \\
(19.6-25.4)\end{array}$ & $\begin{array}{l}23.4 \pm 1.8 \\
(20.4-27.3)\end{array}$ & $\begin{array}{l}23.6 \pm 2.1 \\
(21.4-28.9)\end{array}$ & $\begin{array}{l}24.2 \pm 2.1 \\
(21.6-31.2)\end{array}$ & $\begin{array}{l}26.0 \pm 2.8 \\
(23.3-35.7)\end{array}$ & $\begin{array}{l}27.8 \pm 3.2 \\
(22.8-38.5)\end{array}$ & $\begin{array}{l}31.9 \pm 2.2^{\mathrm{a}} \\
(28.2-35.4)\end{array}$ \\
\hline RER & $\begin{array}{c}0.82 \pm 0.06 \\
(0.75-0.92)\end{array}$ & $\begin{array}{c}0.92 \pm 0.06 \\
(0.81-1.05)\end{array}$ & $\begin{array}{c}0.97 \pm 0.06 \\
(0.87-1.07)\end{array}$ & $\begin{array}{r}0.95 \pm 0.04 \\
(0.88-1.02)\end{array}$ & $\begin{array}{r}0.97 \pm 0.05 \\
(0.87-1.05)\end{array}$ & $\begin{array}{r}1.00 \pm 0.05 \\
(0.90-1.05)\end{array}$ & $\begin{array}{c}1.04 \pm 0.05 \\
(0.95-1.11)\end{array}$ & $\begin{array}{c}1.16 \pm 0.08^{\mathrm{a}} \\
(1.00-1.29)\end{array}$ \\
\hline HR (beats $\min ^{-1}$ ) & $\begin{array}{c}113 \pm 11 \\
(96-126)\end{array}$ & $\begin{array}{l}132 \pm 12 \\
(109-148)\end{array}$ & $\begin{array}{l}149 \pm 15 \\
(131-172)\end{array}$ & $\begin{array}{l}156 \pm 14 \\
(126-175)\end{array}$ & $\begin{array}{l}162 \pm 15 \\
(129-181)\end{array}$ & $\begin{array}{l}169 \pm 14 \\
(137-191)\end{array}$ & $\begin{array}{l}176 \pm 13 \\
(146-195)\end{array}$ & $\begin{array}{c}191 \pm 11^{\mathrm{a}} \\
(181-206)\end{array}$ \\
\hline HR ( $\%$ of peak) & $\begin{array}{l}57.6 \pm 4.4 \\
(49.5-66.8)\end{array}$ & $\begin{array}{l}67.5 \pm 4.7 \\
(58.8-75.4)\end{array}$ & $\begin{array}{l}75.9 \pm 5.5 \\
(67.5-85.6)\end{array}$ & $\begin{array}{c}79.5 \pm 5.2 \\
(68.4-89.2)\end{array}$ & $\begin{array}{l}82.6 \pm 5.1 \\
(73.7-93.8)\end{array}$ & $\begin{array}{l}86.3 \pm 4.9 \\
(78.7-97.9)\end{array}$ & $\begin{array}{l}89.2 \pm 3.7 \\
(83.2-98.1)\end{array}$ & $\begin{array}{c}97.0 \pm 1.7^{\mathrm{a}} \\
(93.6-99.2)\end{array}$ \\
\hline RPE & $7.6 \pm 1.1(7-11)$ & $9.9 \pm 1.0(9-12)$ & $\begin{array}{c}11.8 \pm 1.0 \\
(10-14)\end{array}$ & $\begin{array}{c}12.9 \pm 0.8 \\
(12-15)\end{array}$ & $\begin{array}{c}13.8 \pm 0.9 \\
(13-15)\end{array}$ & $\begin{array}{c}15.0 \pm 1.0 \\
(13-17)\end{array}$ & $\begin{array}{c}16.5 \pm 0.9 \\
(15-18)\end{array}$ & $\begin{array}{c}18.9 \pm 0.9 \\
(17-20)\end{array}$ \\
\hline RPE (\% of peak) & $\begin{array}{l}40.3 \pm 6.3 \\
(36.8-47.1)\end{array}$ & $\begin{array}{l}52.7 \pm 5.4 \\
(47.4-63.2)\end{array}$ & $\begin{array}{l}62.4 \pm 5.4 \\
(52.6-66.7)\end{array}$ & $\begin{array}{l}68.6 \pm 5.0 \\
(63.2-77.8)\end{array}$ & $\begin{array}{l}73.0 \pm 4.7 \\
(68.4-83.3)\end{array}$ & $\begin{array}{c}79.5 \pm 5.4 \\
(73.7-88.9)\end{array}$ & $\begin{array}{l}87.6 \pm 4.8 \\
(78.9-94.1)\end{array}$ & $\begin{array}{l}100 \pm 0 \\
(100-100)\end{array}$ \\
\hline $\begin{array}{l}\text { Blood lactate } \\
\left(\mathrm{mmol} \mathrm{l}^{-1}\right)\end{array}$ & $\begin{array}{c}1.2 \pm 0.6 \\
(0.6-2.5)\end{array}$ & $\begin{array}{c}1.5 \pm 0.7 \\
(0.8-3.2)\end{array}$ & $\begin{array}{c}2.5 \pm 0.9 \\
(1.2-4.9)\end{array}$ & $\begin{array}{c}2.4 \pm 1.1 \\
(0.8-6.1)\end{array}$ & $\begin{array}{c}2.8 \pm 1.2 \\
(1.5-6.8)\end{array}$ & $\begin{array}{l}3.9 \pm 1.5 \\
(2.0-7.9)\end{array}$ & $\begin{array}{c}5.1 \pm 1.9 \\
(3.2-9.8)\end{array}$ & $\begin{array}{l}9.8 \pm 1.7 \\
(6.4-12.9)\end{array}$ \\
\hline
\end{tabular}

${ }^{a}$ Data included only from those participants who completed at least $2 \mathrm{~min}$ on the final stage $(\mathrm{n}=13)$.

Table 3

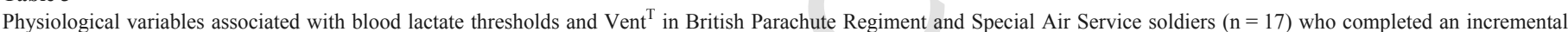

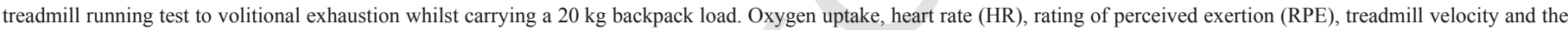

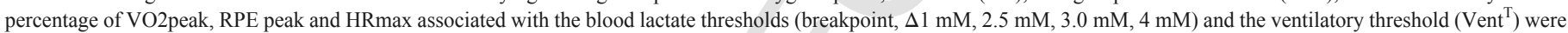
determined from the exercise test. Values are mean \pm SD. Lower and upper limits are shown in parenthesis.

\begin{tabular}{|c|c|c|c|c|c|c|}
\hline & \multicolumn{6}{|c|}{ Blood lactate/Ventilatory threshold } \\
\hline & Breakpoint & $\Delta 1 \mathrm{mmol} \mathrm{l}^{-1}$ & $2.5 \mathrm{mmol} \mathrm{l}^{-1}$ & $3 \mathrm{mmol} \mathrm{l}^{-1}$ & $4 \mathrm{mmol} \mathrm{l}^{-1}$ (OBLA) & Vent $^{\mathrm{T}}$ \\
\hline $\mathrm{VO}_{2}\left(1 \mathrm{~min}^{-1}\right)$ & $\begin{array}{c}2.93 \pm 0.41 \\
(1.84-3.47)\end{array}$ & $\begin{array}{c}3.03 \pm 0.38 \\
(2.19-3.60)\end{array}$ & $\begin{array}{c}3.13 \pm 0.40 \\
(2.09-3.82)\end{array}$ & $\begin{array}{c}3.30 \pm 0.38 \\
(2.25-3.98)\end{array}$ & $3.49 \pm 0.39(2.5-4.28)$ & $3.1 \pm 0.28(2.65-3.5)$ \\
\hline $\mathrm{VO}_{2}\left(\mathrm{ml} \mathrm{kg}^{-1} \min ^{-1}\right)$ & $37.1 \pm 5.2(27.5-43.9)$ & $38.3 \pm 4.8(27.7-45.8)$ & $39.6 \pm 4.7(26.5-45.7)$ & $41.8 \pm 4.7(28.5-47.8)$ & $44.2 \pm 4.8(31.6-49.5)$ & $38.6 \pm 3.3(33.8-45.0)$ \\
\hline $\mathrm{VO}_{2}(\%$ of peak $)$ & $67.7 \pm 8.8(53.0-79.9)$ & $69.7 \pm 6.8(52.3-81.0)$ & $72.3 \pm 8.1(49.9-84.6)$ & $76.2 \pm 7.1(53.7-86.5)$ & $80.4 \pm 6.5(59.7-88.3)$ & $70.4 \pm 4.4(63.4-78.4)$ \\
\hline HR (beats $\min ^{-1}$ ) & $152 \pm 18(111-171)$ & $155 \pm 16(126-182)$ & $159 \pm 17(121-187)$ & $165 \pm 16(129-188)$ & $170 \pm 14(140-187)$ & $157 \pm 14(124-176)$ \\
\hline HR ( $\%$ of peak) & $77.6 \pm 8.5(53.9-87.7)$ & $79.1 \pm 6.5(65.3-90.3)$ & $81.4 \pm 7.0(62.9-93.1)$ & $84.1 \pm 6.0(66.9-93.1)$ & $86.7 \pm 5.0(72.7-94.4)$ & $80.3 \pm 4.7(71.1-88.0)$ \\
\hline RPE & $12.4 \pm 2.0(7.5-15.4)$ & $12.8 \pm 1.8(8.4-15.4)$ & $13.3 \pm 2.0(7.6-16)$ & $14.2 \pm 1.7(8.9-16.5)$ & $15.2 \pm 1.5(10.8-17.1)$ & $13.0 \pm 0.9(11.2-14.4)$ \\
\hline RPE (\% of peak) & $\begin{array}{r}65.5 \pm 10.7 \\
(47.9-77.8)\end{array}$ & $67.6 \pm 9.6(47.9-77.8)$ & $70.5 \pm 8.5(42.0-82.2)$ & $75.0 \pm 8.5(49.4-84.9)$ & $80.7 \pm 7.3(60.2-90.1)$ & $68.9 \pm 4.2(59.0-75.7)$ \\
\hline Treadmill velocity $\left(\mathrm{km} \mathrm{h}^{-1}\right)$ & $9.3 \pm 1.3(7.0-11.5)$ & $9.5 \pm 1.1(6.9-12)$ & $10.0 \pm 1.3(6.6-11.7)$ & $10.7 \pm 1.2(7.1-12.5)$ & $11.8 \pm 1.2(7.9-13)$ & $9.6 \pm 0.5(8.6-10.6)$ \\
\hline
\end{tabular}

$(\mathrm{p}<0.05)$. Relative oxygen uptake at the onset of blood lactate accumulation (OBLA; $4 \mathrm{mmol}^{-1}$ ) and $\mathrm{Vent}^{\mathrm{T}}$ were also associated with performance on the field test $(\mathrm{p}<0.05)$. Fitted line plots showing relationships between field test performance and those independent variables with $r>0.75$ or $<-0.75$ are shown in Fig. 1 . Line of best-fit equations and $\mathrm{R}^{2}$ values are also shown (Fig. 2).

\section{Discussion}

This study determined the physiological responses to a simulated backpack load carriage task in a controlled laboratory setting using an incremental treadmill protocol for a homogenous group of elite sol- diers. The efficacy of the physiological responses measured in the laboratory to predict future backpack running performance in a field setting was also determined. The novel aspects of this study are: (i) the comprehensive analysis of physiological responses to simulated backpack load carriage task in a population of elite soldiers; and (ii) the observation that lactate thresholds (LTs) and backpack walking/running economy, measured under controlled laboratory conditions, are strong indicators of future backpack running performance in a field setting.

This is the first study to provide comprehensive physiological data in response to a simulated load carriage task in elite soldiers. Despite the wide use of LTs and running economy as predictors of future endurance performance in events such as running, rowing and cycling 
Table 4

Correlation coefficients (r) showing relationships between the physiological variables measured during each stage of the treadmill running protocol and performance (run time) on the 8 -mile backpack run test $(n=10)$. Statistically significant association indicated by $*(\mathrm{p}<0.05)$ and $* *(\mathrm{p}<0.01)$.

\begin{tabular}{|c|c|c|c|c|c|c|c|c|}
\hline & \multicolumn{8}{|c|}{ Treadmill velocity $\left(\mathrm{km} \mathrm{h}^{-1}\right)$} \\
\hline & 6.4 & 7.4 & 8.4 & 9.4 & 10.4 & 11.4 & 12.4 & $\begin{array}{l}\text { Final } \\
\text { stage }\end{array}$ \\
\hline $\mathrm{VO}_{2}\left(1 \min ^{-1}\right)$ & 0.55 & 0.54 & 0.39 & 0.41 & 0.41 & 0.45 & 0.43 & $0.35^{\mathrm{a}}$ \\
\hline $\begin{array}{l}\mathrm{VO}_{2} \\
\left(\mathrm{ml} \mathrm{kg}^{-1} \mathrm{~min}^{-1}\right)\end{array}$ & $0.76^{*}$ & $0.80 * *$ & 0.62 & 0.59 & 0.61 & $0.66^{*}$ & $0.65^{*}$ & $0.49^{\mathrm{a}}$ \\
\hline $\mathrm{VO}_{2}(\%$ of peak $)$ & 0.43 & 0.46 & 0.22 & 0.32 & 0.36 & 0.55 & 0.55 & $0.26^{\mathrm{a}}$ \\
\hline$V_{E}\left(1 \min ^{-1}\right)$ & 0.54 & 0.62 & 0.42 & 0.43 & 0.52 & 0.50 & 0.63 & $0.36^{\mathrm{a}}$ \\
\hline $\mathrm{V}_{\mathrm{E}} / \mathrm{VO}_{2}$ & 0.19 & 0.27 & 0.15 & -0.10 & 0.25 & 0.04 & 0.37 & $-0.21^{\mathrm{a}}$ \\
\hline RER & 0.59 & 0.63 & 0.48 & 0.41 & $0.66^{*}$ & 0.62 & $0.66^{*}$ & $0.25^{\mathrm{a}}$ \\
\hline HR (beats $\min ^{-1}$ ) & 0.38 & 0.41 & 0.46 & 0.48 & 0.50 & 0.45 & 0.48 & $0.66^{\mathrm{a}}$ \\
\hline HR ( $\%$ of peak) & 0.14 & 0.15 & 0.22 & 0.23 & 0.28 & 0.16 & 0.12 & $0.68^{\mathrm{a}}$ \\
\hline RPE & 0.27 & 0.07 & 0.37 & 0.39 & -0.06 & 0.16 & 0.34 & 0.29 \\
\hline RPE (\% of peak) & 0.13 & -0.12 & 0.18 & 0.01 & -0.46 & -0.22 & 0.02 & - \\
\hline $\begin{array}{l}\text { Blood lactate } \\
\left(\mathrm{mmol} \mathrm{l}^{-1}\right)\end{array}$ & 0.34 & -0.44 & -0.07 & 0.44 & 0.65 & 0.14 & 0.19 & -0.52 \\
\hline
\end{tabular}

${ }^{a}$ Regression coefficients include only those participants who completed at least $2 \mathrm{~min}$ on the final stage $(n=7)$.

(Faude et al., 2009), these standard laboratory tests have largely been neglected as potential performance predictors of backpack load-carriage tasks in soldiers. In accordance with the definitions of Weltman (Weltman, 1995), the average breakpoint, $\Delta 1 \mathrm{mmol}^{-1}$ and the onset of blood lactate accumulation (OBLA; $4 \mathrm{mmol} \mathrm{l}^{-1}$ ) LTs for this group of soldiers carrying a standard $20 \mathrm{~kg}$ backpack load, was $\sim 9.3, \sim 9.5$ and $\sim 11.8 \mathrm{~km} \mathrm{~h}^{-1}$, respectively. The combat fitness test for conventional British soldiers is to complete an 8-mile enforced march over undulating terrain carrying a $20 \mathrm{~kg}$ backpack load within $120 \mathrm{~min}$ (average pace: $6.4 \mathrm{~km} \mathrm{~h}^{-1}$ ). In the present study, average blood lactate levels at this velocity were at resting values $\left(\sim 1.2 \mathrm{mmol} \mathrm{l}^{-1}\right)$ and the rating of perceived exertion (RPE) scores at 7-8 ('extremely light' on the Borg 6-20 scale). Moreover, the average completion time of 88.6 min (average speed: $8.71 \mathrm{~km} \mathrm{~h}^{-1}$ ) in the field test was less than $3 / 4$ of the time expected for conventional British troops to complete this distance, and is similar to the average velocity attained by trained men (VO2peak: $4.30 \pm 0.461 \mathrm{~min}^{-1} ; 53.03 \pm 3.21 \mathrm{ml} \mathrm{kg} \mathrm{min}^{-1}$ ) over shorter time trial distances $(2.4 \mathrm{~km})$ under controlled laboratory conditions (Faghy and Brown, 2014). These data underscore the advanced physiological capabilities of elite soldiers compared to both non-soldiers and conventional infantry soldiers, and also indicate that the physiological demands of backpack running performance across different subject groups should be interpreted with caution.
Our additional aim was to establish the efficacy of the identified physiological laboratory measures for predicting performance in an 8-mile backpack load carriage task conducted in a field setting. Using the LT definitions provided by Weltman (Weltman, 1995), we established that treadmill-running velocity and RPE at both the breakpoint and $\Delta 1 \mathrm{mmol}^{-1}$ LTs were the best indicators of 8-mile backpack run time in a simulated field setting (Table 5). Relative oxygen uptake at OBLA and submaximal backpack walking velocities of 6.4 and $7.4 \mathrm{~km} \mathrm{~h}^{-1}$ were also strongly indicative of performance, with lower oxygen uptakes at OBLA and these velocities being associated with faster 8-mile run times. The 10 soldiers who completed the field test had an average breakpoint LT of $9.1 \mathrm{~km} \mathrm{~h}^{-1}$. Assuming this velocity represents the maximum average pace that can be maintained over 1-2 h (Faude et al., 2009), the average time to complete the 8-mile $(12.87 \mathrm{~km})$ distance was not expected to be quicker than $84 \mathrm{~min}$. The actual average field-test time of $88.6 \mathrm{~min}$ was within $5.5 \%$ of this predicted completion time, which we consider a good estimate given the extraneous factors that are difficult to control in field conditions (i.e. undulating terrain, environmental factors).

The 8-mile backpack run test was completed at an average speed of $8.71 \mathrm{~km} \mathrm{~h}^{-1}$ for this group of soldiers. It is perhaps surprising, therefore, that no physiological measures obtained at the closest running speeds on the treadmill $\left(8.4 \mathrm{~km} \mathrm{~h}^{-1}\right.$ or $\left.9.4 \mathrm{~km} \mathrm{~h}^{-1}\right)$ were associated with performance on the field test. This might be due to the pacing strategy adopted by these experienced soldiers in the field test, where they would typically walk during the uphill sections and run on the flat and downhill sections of the undulating course. Moreover, at the $8.4 \mathrm{~km} \mathrm{~h}^{-1}$ treadmill velocity, some soldiers maintained a walking gait while others transitioned to running, possibly resulting in erroneous physiological data being collected at that stage of the protocol. Despite this, relative oxygen uptake at the $6.4 \mathrm{~km} \mathrm{~h}^{-1}$, $7.4 \mathrm{~km} \mathrm{~h}^{-1}, 11.4 \mathrm{~km} \mathrm{~h}^{-1}$, and $12.4 \mathrm{~km} \mathrm{~h}^{-1}$ treadmill velocities was associated with field test performance, indicating that backpack walking/running economy at intermittent running speeds are good indicators of backpack running performance, regardless of the average time taken to complete the run. Walking pace $\left(6.4 \mathrm{~km} \mathrm{~h}^{-1}, 7.4 \mathrm{~km} \mathrm{~h}^{-1}\right)$ economy was actually a stronger indicator of field test performance than running pace $\left(11.4 \mathrm{~km} \mathrm{~h}^{-1}, 12.4 \mathrm{~km} \mathrm{~h}^{-1}\right)$ economy, despite all soldiers completing the 8-mile time trial at an average pace that was faster than their elected walk-run transition speed on the treadmill.

Peak oxygen uptake measured in the laboratory was unrelated to field test performance, confirming our previous findings that VO2peak measured during a backpack load carriage task is not predictive of backpack running performance in field conditions (Simpson et al., 2006). While peak oxygen uptake may be a better determinant of heavy ( $>40 \%$ of body mass) load-carriage performance (Lyons et al.,

Table 5

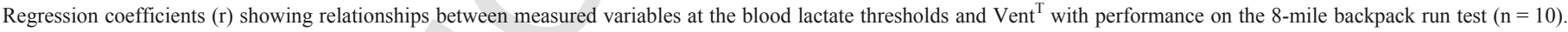
Statistically significant association indicated by $*(\mathrm{p}<0.05)$ and $* *(\mathrm{p}<0.01)$. OBLA: onset of blood lactate accumulation.

\begin{tabular}{|c|c|c|c|c|c|c|}
\hline & \multicolumn{6}{|c|}{ Blood Lactate/Ventilatory thresholds } \\
\hline & Breakpoint & $\Delta 1 \mathrm{mmol} \mathrm{l}^{-1}$ & $2.5 \mathrm{mmol} \mathrm{l}^{-1}$ & $3.0 \mathrm{mmol} \mathrm{l}^{-1}$ & $4.0 \mathrm{mmol} \mathrm{l}^{-1}$ (OBLA) & Vent $^{\mathrm{T}}$ \\
\hline $\mathrm{VO}_{2}\left(1 \mathrm{~min}^{-1}\right)$ & -0.28 & 0.10 & 0.19 & 0.25 & 0.47 & 0.45 \\
\hline $\mathrm{VO}_{2}\left(\mathrm{ml} \cdot \mathrm{kg}^{-1} \min ^{-1}\right)$ & -0.28 & 0.07 & 0.34 & 0.47 & $0.76^{*}$ & $0.66^{*}$ \\
\hline $\mathrm{VO}_{2}(\%$ of peak $)$ & -0.59 & -0.52 & -0.21 & -0.19 & 0.35 & 0.28 \\
\hline HR (beats $\min ^{-1}$ ) & -0.40 & 0.04 & 0.22 & 0.35 & 0.52 & 0.47 \\
\hline HR (\% of peak) & -0.63 & -0.38 & -0.24 & -0.19 & 0.17 & 0.17 \\
\hline RPE & $-0.79 * *$ & $-0.68^{*}$ & -0.34 & -0.38 & -0.17 & -0.07 \\
\hline RPE (\% of peak) & $-0.80 * *$ & $-0.75^{*}$ & -0.49 & -0.60 & -0.43 & 0.43 \\
\hline Treadmill velocity $\left(\mathrm{km} \mathrm{h}^{-1}\right)$ & $-0.85 * *$ & $-0.80 * *$ & -0.47 & -0.55 & -0.34 & -0.28 \\
\hline
\end{tabular}



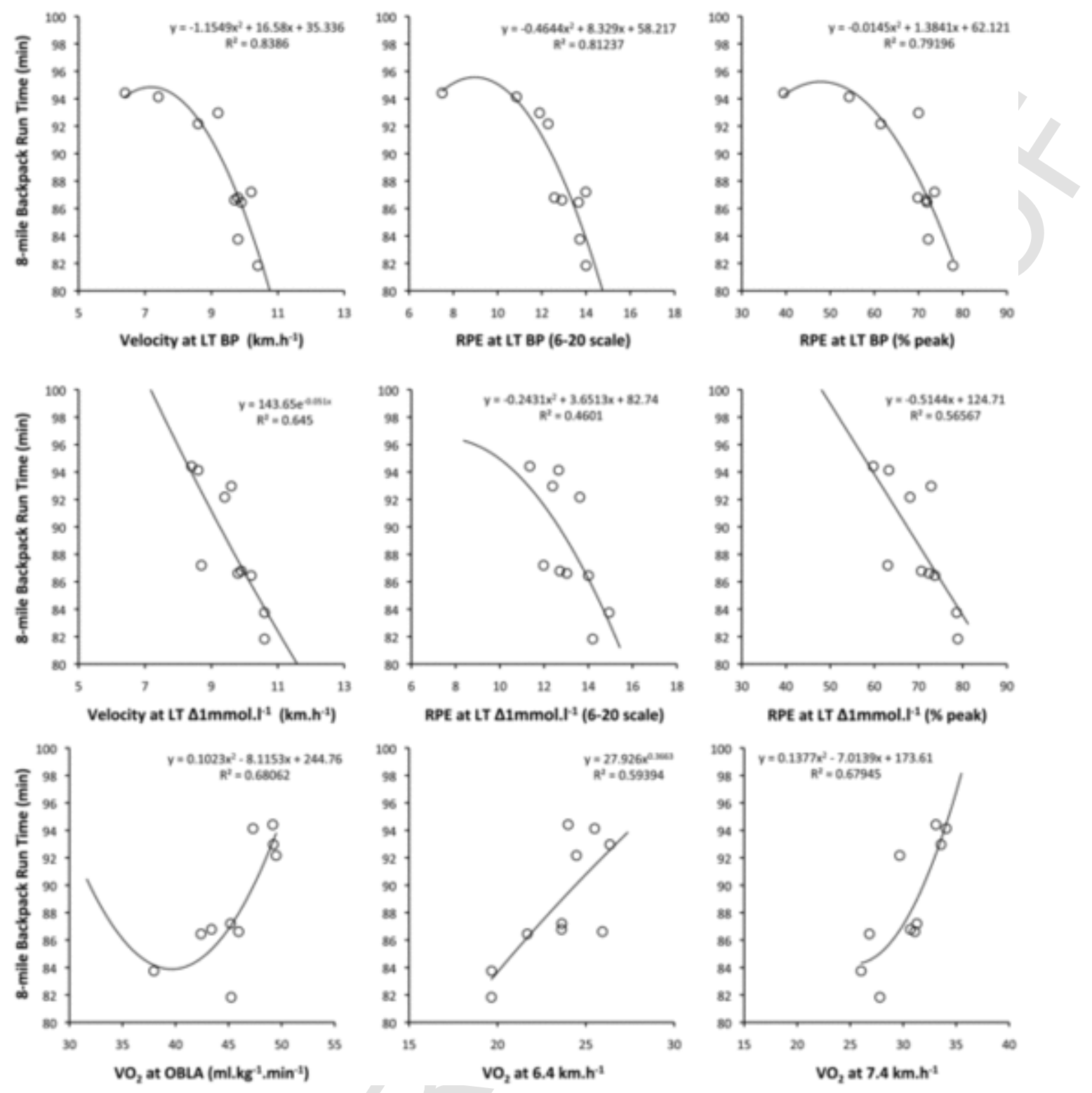

Figure 2. Fitted-line plots of the nine variables identified with $r$-values of $>0.75$ or $<-0.75$ in relation to 8 -mile Backpack Run Time for the ten participants completing the field test. Solid lines represent the modelled line of the data, with the line of best-fit equation and goodness-of-fit $\left(\mathrm{R}^{2}\right)$ included on each plot. RPE: rating of perceived exertion; LT; lactate threshold; BP: breakpoint; OBLA: onset of blood lactate accumulation.

2005), our findings here support the contention that the ability to carry lighter loads ( $<30 \%$ body weight) at speed is not dependent on peak oxygen uptake (Bilzon et al., 2001; Simpson et al., 2006). Moreover, although we used a standard backpack weight in this study to maintain ecological validity, the backpack weight ranged from 22 to $30 \%$ body weight and was not related to completion time in the field test. In addition to $\mathrm{VO} 2$, previous studies have also found that body mass is positively associated with heavy, but not lighter, backpack load carriage performance (Pandorf et al., 2002), indicating that both physiological and anthropometric indicators of load-carriage performance may be dependent on the loads carried relative to body mass.

Attempts to predict load carriage performance in conventional soldiers have mostly relied on relatively simple measures of physical fitness such as unloaded run time, estimated VO2max, manual resistance exercises (i.e. circuit training), and maximum strength (Pandorf et al., 2002; Williams and Rayson, 2006; Williams et al., 2004). The equivocal findings in the literature would indicate that the physiological determinants of backpack load carriage performance is rather complex, requiring more sophisticated measures to better profile the physiological demands of backpack running. We found in this study that LTs and backpack walking/running economy measured in the laboratory were strong predictors of future backpack running performance in a field setting, indicating that LTs and economy are major determinants of backpack running performance. Given the large numbers of conventional soldiers requiring assessment, the logistics and expertise required performing these laboratory-based measurements on all, or even a majority of these troops, would be an onerous task. In comparison, with the relatively small number of Special Forces troops, and with a greater perceived requirement to maximize operational performance within these soldiers, we contend that the additional time, resources and expertise necessary to perform these laboratory tests are resources well used. This is clearly evident given the extensive resources required to both select and train a Special Forces 
operator, the capability to accurately predict load carriage performance and set benchmark/baseline data levels would enable the accurate assessment of training interventions designed to optimize future load carriage performance. In addition, the operational requirements of Special Forces troops differ significantly from those of conventional soldiers, and the 8-mile run utilized within the present study would be more representative of the operation demands experienced by this population, as they are routinely required to operate independently in remote locations.

The findings reported here have profound practical applications, in that a relatively simple to administer backpack treadmill protocol can be utilized to analyze load carriage performance, and that LTs and backpack walk/run economy are the most accurate measures for predicting future success in an 8-mile load carriage task for elite British soldiers. We acknowledge, however, that the physiological determinants of successful load-carriage performance may differ when carrying heavier backpack loads and over more arduous (i.e. mountainous) terrain. While elite soldiers may carry much heavier operational loads ( $>45 \%$ body weight), we selected the standard backpack weight of $20 \mathrm{~kg}$, as this is a typical load carried by soldiers during standardized combat fitness tests. Future studies should attempt to establish the efficacy of LTs and backpack walk/run economy as predictors of future backpack load-carriage performance in elite soldiers carrying multiple backpack loads across various terrains and distances to understand the factors that determine optimal pacing strategies. A recognised limitation of this study is the use of the univariate correlational analysis. Our decision not to use multiple regression analysis was due to the relatively small sample size. However, given the strong associations reported here, it is likely that LTs and backpack walking/running economy will account for a large proportion of the variance when attempting to predict load-carriage performance in elite soldiers using multiple regression models, and we suggest that future studies should assess these physiological responses to backpack load-carriage tasks in a larger number of participants.

\section{Conclusions}

We have shown for the first time that BLTs and backpack walking/ running economy are major determinants of 8-mile backpack running performance in field conditions for this group of elite soldiers carrying loads of $22-30 \%$ body weight. Physical training instructors and exercise physiologists working with both elite and conventional soldiers should consider incorporating blood lactate threshold testing during simulated load carriage tasks to monitor training adaptations and to predict performance in aspiring recruits.

\section{Acknowledgments}

This work was supported by a Student Vacation Scholarship from the Carnegie Trust for the Universities of Scotland (to R. Clement).

\section{References}

Allsopp, A.J., Shariff, A., 2004. Improving the selection of candidates for royal marine recruit training by the use of a combination of performance tests. J. R. Nav. Med. Serv. 90, 117-124.

Beekley, M.D., Alt, J., Buckley, C.M., Duffey, M., Crowder, T.A., 2007. Effects of heavy load carriage during constant-speed, simulated, road marching. Mil. Med. 172, 592-595.

Bilzon, J.L., Allsopp, A.J., Tipton, M.J., 2001. Assessment of physical fitness for occupations encompassing load-carriage tasks. Occup. Med. (Lond) 51, 357-361.

Borg, G., 1998. Borg's Perceived Exertion and Pain Scales. Human Kinetics, Champaign, IL.

Christie, C.J., Scott, P.A., 2005. Metabolic responses of South African soldiers during simulated marching with 16 combinations of speed and backpack load. Mil. Med. 170, 619-622.

Faghy, M.A., Brown, P.I., 2014. Preloaded time trial to assess load carriage performance. J. Strength Cond. Res. 28, 3354-3362.

Faude, O., Kindermann, W., Meyer, T., 2009. Lactate threshold concepts: how valid are they?. Sports Med. 39, 469-490.

Gaskill, S.E., Ruby, B.C., Walker, A.J., Sanchez, O.A., Serfass, R.C., Leon, A.S., 2001. Validity and reliability of combining three methods to determine ventilatory threshold. Med. Sci. Sports Exerc 33, 1841-1848.

Haisman, M.F., 1988. Determinants of load carrying ability. Appl. Ergon. 19, 111-121.

Jones, A.M., Doust, J.H., 1996. A 1\% treadmill grade most accurately reflects the energetic cost of outdoor running. J. Sports Sci. 14, 321-327.

Lyons, J., Allsopp, A., Bilzon, J., 2005. Influences of body composition upon the relative metabolic and cardiovascular demands of load-carriage. Occup. Med. (Lond) 55, 380-384.

Pandorf, C.E., Harman, E.A., Frykman, P.N., Patton, J.F., Mello, R.P., Nindl, B.C., 2002. Correlates of load carriage and obstacle course performance among women. Work 18, 179-189.

Rayson, M., Holliman, D., Belyavin, A., 2000. Development of physical selection procedures for the British Army. Phase 2: relationship between physical performance tests and criterion tasks. Ergonomics 43, 73-105.

Saunders, P.U., Pyne, D.B., Telford, R.D., Hawley, J.A., 2004. Factors affecting running economy in trained distance runners. Sports Med. 34, 465-485.

Simpson, R.J., Graham, S.M., Florida-James, G.D., Connaboy, C., Clement, R., Jackson, A.S., 2010. Perceived exertion and heart rate models for estimating metabolic workload in elite British soldiers performing a backpack load-carriage task. Appl. Physiol. Nutr. Metab. 35, 650-656.

Simpson, R.J., Gray, S.C., Florida-James, G.D., 2006. Physiological variables and performance markers of serving soldiers from two "elite" units of the British Army. J. Sports Sci. 24, 597-604.

Weltman, A., 1995. The Blood Lactate Response to Exercise. Human Kinetics, Champaign, IL

Wilkinson, D.M., Rayson, M.P., Bilzon, J.L., 2008. A physical demands analysis of the 24-week British Army Parachute Regiment recruit training syllabus. Ergonomics 51, 649-662.

Williams, A.G., Rayson, M.P., 2006. Can simple anthropometric and physical performance tests track training-induced changes in maximal box-lifting ability?. Ergonomics 49, 661-670.

Williams, A.G., Rayson, M.P., Jones, D.A., 2004. Training diagnosis for a load carriage task. J. Strength Cond. Res. 18, 30-34. 